University of Nebraska - Lincoln

DigitalCommons@University of Nebraska - Lincoln

Faculty Publications: Department of

Entomology

Entomology, Department of

December 2003

\title{
In-Field Labeling of Western Corn Rootworm Adults (Coleoptera: Chrysomelidae) with Rubidium
}

Timothy M. Nowatzki

University of Nebraska-Lincoln

Bradley Niimi

University of Nebraska-Lincoln

Kelli J. Warren

University of Nebraska-Lincoln

Sean Putnam

University of Nebraska-Lincoln, sputnam@lps.org

Lance J. Meinke

University of Nebraska-Lincoln, Imeinke1@unl.edu

See next page for additional authors

Follow this and additional works at: https://digitalcommons.unl.edu/entomologyfacpub

Part of the Entomology Commons

Nowatzki, Timothy M.; Niimi, Bradley; Warren, Kelli J.; Putnam, Sean; Meinke, Lance J.; Gosselin, David C.; Harvey, F. Edwin; Hunt, Thomas E.; and Siegfried, Blair D., "In-Field Labeling of Western Corn Rootworm Adults (Coleoptera: Chrysomelidae) with Rubidium" (2003). Faculty Publications: Department of Entomology. 41.

https://digitalcommons.unl.edu/entomologyfacpub/41

This Article is brought to you for free and open access by the Entomology, Department of at DigitalCommons@University of Nebraska - Lincoln. It has been accepted for inclusion in Faculty Publications: Department of Entomology by an authorized administrator of DigitalCommons@University of Nebraska - Lincoln. 


\section{Authors}

Timothy M. Nowatzki, Bradley Niimi, Kelli J. Warren, Sean Putnam, Lance J. Meinke, David C. Gosselin, F. Edwin Harvey, Thomas E. Hunt, and Blair D. Siegfried 


\section{In-Field Labeling of Western Corn Rootworm Adults (Coleoptera: Chrysomelidae) with Rubidium}

Timothy M. Nowatzki, Bradly Niimi, Kelli J. Warren, Sean Putnam, Lance J. Meinke, David C. Gosselin, F. Edwin Harvey, Thomas E. Hunt, and Blair D. Siegfried

Journal of Economic Entomology

Volume 96, Issue 6 (December 2003) pp. 1750-1759

DOI: 10.1603/0022-0493(2003)096[1 750:ILOWCR]2.0.CO;2

Authors may post electronic reprints of their own journal articles after an embargo period of two years has passed from the date of publication. Also, authors must include on the electronic reprint the following statement:

This article is the copyright property of the Entomological Society of America and may not be used for any commercial or other private purpose without specific written permission of the Entomological Society of America. 


\title{
In-Field Labeling of Western Corn Rootworm Adults (Coleoptera: Chrysomelidae) with Rubidium
}

\author{
TIMOTHY M. NOWATZKI, BRADLY NIIMI, KELLI J. WARREN, ${ }^{1}$ SEAN PUTNAM, \\ LANCE J. MEINKE, DAVID C. GOSSELIN, ${ }^{1}$ F. EDWIN HARVEY, ${ }^{1}$ THOMAS E. HUNT, ${ }^{2}$ \\ AND BLAIR D. SIEGFRIED ${ }^{3}$
}

Department of Entomology, University of Nebraska-Lincoln, 202 Plant Industry Bldg., Lincoln, NE 68583-0816

\section{J. Econ. Entomol. 96(6): 1750-1759 (2003)}

\begin{abstract}
Field and laboratory studies were conducted in 2000 and 2001 to determine the feasibility of mass marking western corn rootworm adults, Diabrotica virgifera virgifera LeConte, with $\mathrm{RbCl}$ in the field. Results showed that application of rubidium $(\mathrm{Rb})$ in solution to both the soil ( $1 \mathrm{~g} \mathrm{Rb} /$ plant) and whorl ( $1 \mathrm{~g} \mathrm{Rb} /$ plant) of corn plants was optimal for labeling western corn rootworm adults during larval development. Development of larvae on Rb-enriched corn with this technique did not significantly influence adult dry weight or survival. Rb was also highly mobile in the plant. Application of $\mathrm{Rb}$ to both the soil and the whorl resulted in median $\mathrm{Rb}$ concentrations in the roots $(5,860 \mathrm{ppm})$ that were 150 -fold greater than concentrations in untreated roots $(38 \mathrm{ppm}) 5 \mathrm{wk}$ after treatment. Additionally, at least $90 \%$ of the beetles that emerged during the first $3 \mathrm{wk}$ were labeled above the baseline $\mathrm{Rb}$ concentration ( 5 ppm dry weight) determined from untreated beetles. Because emergence was $72 \%$ complete at this time, a significant proportion of the population had been labeled. Results from laboratory experiments showed that labeled beetles remained distinguishable from unlabeled beetles for up to $4 \mathrm{~d}$ postemergence. The ability to efficiently label large numbers of beetles under field conditions and for a defined period with virtually no disruption of the population provides an unparalleled opportunity to conduct mark-recapture experiments for quantifying the short-range, intrafield movement of adult corn rootworms.
\end{abstract}

KEY WORDS western corn rootworm, Diabrotica virgifera, rubidium, mark-recapture, Zea mays

DEVELOPING EFFECTIVE PEST management strategies for insects requires a detailed understanding of their lifehistory and population dynamics. A key component of western corn rootworm, Diabrotica virgifera virgifera LeConte, population dynamics in field corn, Zea mays L., is adult dispersal. Western corn rootworm adults are capable of both intra- (Darnell et al. 2000) and interfield dispersal (Godfrey and Turpin 1983, Naranjo 1991). Beetle movement between cornfields is often related to changes in corn plant phenology that affects food quality within the field (Hill and Mayo 1974, Witkowski et al. 1975, Godfrey and Turpin 1983, Naranjo 1991). Beetles tethered to flight mill systems have been used in the laboratory to study the effects of age and reproductive development on flight behavior and to assess differences in flight characteristics between sexes (Coats et al. 1986, Naranjo 1990a). Unfortunately, little data have been collected that quantify the timing and magnitude of intrafield beetle movement relative to emergence sites. This informa-

\footnotetext{
${ }^{1}$ School of Natural Resource Sciences, University of NebraskaLincoln, 309 Biochemistry Hall, Lincoln, NE 68583-0758.

${ }^{2}$ Haskell Agricultural Laboratory, University of Nebraska, 57905 866 Road, Concord, NE 68728.

${ }^{3}$ Corresponding author: E-mail: bsiegfried1@unl.edu.
}

tion has become increasingly important with the development of rootworm-targeted transgenic corn hybrids and the need to design refuges that promote random mating between resistant and susceptible insects and delay the evolution of rootworm resistance (International Life Sciences Institute 1999, U.S. Environmental Protection Agency 2002).

Insect dispersal is often studied by the marking, release, and recapture of insects that have either been collected from field populations or reared in laboratory colonies (Southwood 1978, Graham et al. 1978a). Critical to the success of such studies is formulating a marking technique that can be efficiently applied, causes minimal disruption to the population, persists for a known length of time, and does not cause any negative fitness effects (Akey 1991). Marking techniques previously developed for western corn rootworms in corn include the application of fluorescent dusts to field-collected beetles (Naranjo 1990b, Oloumi-Sadeghi and Levine 1990) and feeding beetles artificial diets treated with colored dyes (Naranjo 1990b, Lance and Elliott 1990). Although both techniques were shown to adequately mark the insects, they both have critical disadvantages that limit their use for mark-recapture studies. First, the number of 
insects that can be manually collected from the field or reared in the laboratory limits the number of insects that can be released. More importantly, movement of insects marked with these techniques is confounded by either the physical disruption of the population that occurs at the time of release or the unnatural, laboratory conditions in which the insects were reared.

In other cropping systems, labeling phytophagous insects with elemental markers, such as rubidium $(\mathrm{Rb})$, has provided an economical, nondisruptive, and environmentally safe method for marking large numbers of insects through their consumption of Rbtreated host plants (Berry et al. 1972, Hayes 1991). Rb is a rare element found at relatively low but variable levels throughout the earth's surface (Stimmann 1991). In Illinois alone, Jones (1989) determined that the $\mathrm{Rb}$ concentration in the soil surface horizons ranged from 40 to $166 \mathrm{ppm}$ across the state. As a result of this geographic variability, when Rb is used in markrecapture studies, it is necessary to determine the baseline concentration of $\mathrm{Rb}$ present in the system above which an insect is considered positively labeled. The baseline $\mathrm{Rb}$ concentration is calculated as the mean concentration in unlabeled, endogenous insect populations $+3 \mathrm{SD}$ above that mean (Van Steenwyk 1991). Because $\mathrm{Rb}$ has chemical properties similar to potassium, it can be applied to the host plant, be taken up systemically, and be accumulated in the insect as it feeds to concentrations higher than levels normally present in the endogenous population (Berry et al. 1972, Hopper 1991).

Such a marking technique should be conducive to labeling western corn rootworms because the larvae are subterranean, relatively immobile, and typically complete their development on corn roots. The objectives of this study were to (1) develop a technique to efficiently label western corn rootworm adults with $\mathrm{Rb}$ in the field; (2) quantify Rb uptake in corn and its partitioning to various plant structures; and (3) determine if the labeling technique would be feasible for studying intrafield movement of western corn rootworm adults.

\section{Materials and Methods}

Field studies were conducted in 2000 and 2001 at the University of Nebraska Agricultural Research and Development Center, near Mead, NE. In both years, plots were established in areas where soybean, Glycine $\max \mathrm{L}$., had been grown the previous season. The experimental design in both years was a randomized complete block with four treatments replicated four times. In 2000, treatments consisted of an untreated control and three rates of $\mathrm{Rb}(0.08,0.40$, and $0.80 \mathrm{~g}$ $\mathrm{Rb} / 30.5-\mathrm{cm}$ row) applied to the soil at the base of each plant. Plots to which treatments were applied contained three rows of corn each $6 \mathrm{~m}$ in length. In 2001, treatments were an untreated control and three $\mathrm{Rb}$ application methods: (1) $1 \mathrm{~g} \mathrm{Rb}$ applied to the soil at the base of each plant; (2) $1 \mathrm{~g} \mathrm{Rb}$ directed into the whorl of each plant; (3) $1 \mathrm{~g} \mathrm{Rb}$ applied to the soil and $1 \mathrm{~g} \mathrm{Rb}$ directed into the whorl of each plant. Plots to which treatments were applied contained three rows of corn each $21 \mathrm{~m}$ in length. Soil type was a Sharpsburg silty clay loam. In April of both years, nitrogen was applied at a rate of $68 \mathrm{~kg} / \mathrm{ha}$, and the plot areas were disked and harrowed before planting. The corn hybrid 33G26 (Pioneer Hi-Bred International, Des Moines, IA) was planted in early May of both years using a four-row Kinze model 2100 (Kinze Manufacturing, Williamsburg, IA) planter with rows spaced $76 \mathrm{~cm}$ apart at a rate of 66,700 seeds/ha. A standard weed control program consisting of both a pre- and postemergence herbicide application was used in both years. In 2000 and 2001, the plots received 26.4 and $23.9 \mathrm{~cm}$ of precipitation, respectively, during June and July as both rainfall and irrigation.

Field Study 2000. Western corn rootworm eggs were obtained from beetles collected near Concord, NE, in 1999 (French Agricultural Research, Lamberton, MN). Eggs were suspended in a $0.125 \%$ solution of agar-water and manually injected with a large syringe $\approx 10-15 \mathrm{~cm}$ into the soil at the base of each plant. All plants in the center row of each treatment were infested at a rate of 350 eggs per plant. Plants were at the two-leaf stage of growth at the time of infestation.

The $\mathrm{Rb}$ treatments were applied on 13 June to the infested corn plants at the six-leaf stage of growth and corresponded to the initiation of egg hatch. Technical grade $\mathrm{RbCl}$ (99\% purity; Aldrich, Milwaukee, WI) was applied as a powder with a bicycle-applicator through a Noble metering unit (Noble Manufacturing, Sioux City, IA). The applicator had a single drop-tube that directed the dry $\mathrm{RbCl}$ to the soil at the base of each infested plant on one side of the row. Immediately after application, the plot was tilled with a row-crop cultivator to incorporate the $\mathrm{Rb}$. A total of $1.1 \mathrm{~cm}$ of rainfall was received during the 12 -h period after application.

The endogenous concentration of $\mathrm{Rb}$ in the soil was determined $4 \mathrm{~d}$ before the treatments were applied by removing a single soil core, $2.5 \mathrm{~cm}$ in diameter, from each treatment. Each core was taken $12 \mathrm{~cm}$ away from the base of a treated plant and was divided by depth into three subsamples, $0-20,20-60$, and $60-122 \mathrm{~cm}$, respectively. To quantify changes in the $\mathrm{Rb}$ concentration of soil over time, a single core per treatment was also extracted 2 and $21 \mathrm{wk}$ after treatment. However, for soil samples taken $2 \mathrm{wk}$ after treatment, only two depths were sampled, $0-20$ and $20-60 \mathrm{~cm}$. Soil samples were dried at $65^{\circ} \mathrm{C}$ for $4-5 \mathrm{~d}$ and stored in sealed containers.

Partitioning of $\mathrm{Rb}$ in the plants was examined by removing tissue samples from two plants per treatment. Plants were sampled $4 \mathrm{~d}$ pretreatment, and at two and $8 \mathrm{wk}$ posttreatment. Samples were removed from three positions: 1) roots; 2) lower leaf (lowest green leaf in its entirety); and 3) stalk (included node where lower leaf was attached plus internode below that point). Root samples were obtained by extracting each root mass from the soil and washing it free of soil with pressurized water. Each root sample consisted of a vertical cross-section of the nodal roots that were cut from one side of each root mass. Plant samples were 
dried at $65^{\circ} \mathrm{C}$ for $4-5 \mathrm{~d}$ and stored in sealed containers.

$\mathrm{Rb}$ concentrations in newly emerged beetles were determined from beetles collected in two screen emergence cages per treatment, each with an area of 76 x $43 \mathrm{~cm}$. Each cage was positioned across the row and was centered over a single plant, but encompassed an area equivalent to two plants (the center plant and half the root system of the plant located on each side). Cage placement required cutting the corn stalk near its base, setting the cage over the cut plant, and sealing the wood base with soil. Beetles were captured in a $473 \mathrm{ml}$ glass jar attached to the screen at the top of each cage. Beetles were collected from the jars at $3-4$-d intervals for $5 \mathrm{wk}$ and stored at $-20^{\circ} \mathrm{C}$.

Field Study 2001. On 23 May, western corn rootworm eggs (same source as 2000) were manually infested to 20 consecutive plants in the center row of each treatment at a rate of 200 eggs per plant. Plants were at the two-leaf stage of growth at the time of infestation. On 7 June, the Rb treatments were applied to the infested plants at the six-leaf stage of growth. Technical grade $\mathrm{RbCl}$ was applied in solution to the infested plants with a Labmax 10-ml bottle top dispenser (VWR Scientific Products, Willard, OH). For treatments applied to the soil, the $\mathrm{RbCl}$ solution $(10 \mathrm{ml}$ per plant) was dispensed to the soil surface around the base of each infested plant. For the whorl treatments, $5 \mathrm{ml}$ of the $\mathrm{RbCl}$ solution was dispensed directly into the whorl of each infested plant. The plot was tilled with a row-crop cultivator $5 \mathrm{~d}$ after treatment to incorporate the $\mathrm{Rb}$ applied to soil.

$\mathrm{Rb}$ concentrations in the soil were determined by extracting three soil cores per treatment 5 and $8 \mathrm{wk}$ after treatment. Each core was taken $12 \mathrm{~cm}$ away from the base of a treated plant and was divided by depth into two subsamples, $0-20$ and $20-60 \mathrm{~cm}$, respectively. Soil samples were dried at $65^{\circ} \mathrm{C}$ for $4-5 \mathrm{~d}$ and stored in sealed containers. Three plants per treatment were sampled 5 and $8 \mathrm{wk}$ after treatment to examine the partitioning of $\mathrm{Rb}$ in the plants. On each date, samples were removed from five positions per plant: (1) the roots; (2) lower leaf (the lowest green leaf in its entirety); (3) lower stalk (included node where lower leaf was attached plus internode below that point); (4) upper leaf (third leaf from top of the plant in its entirety); and (5) upper stalk (included node where upper leaf was attached plus internode below that point). Root samples were obtained using methods described in the 2000 study. Plant tissue samples were dried at $65^{\circ} \mathrm{C}$ for $4-5 \mathrm{~d}$ and stored in sealed containers. $\mathrm{Rb}$ concentrations in newly emerged beetles were determined from beetles collected in three screen emergence cages per treatment using methods described in the 2000 study. Beetles were collected from the cages at 2- to 3 -d intervals for $6 \mathrm{wk}$ and stored at $-20^{\circ} \mathrm{C}$.

Rb Extraction. Rb concentrations in the soil were determined using methodology similar to that described by Knudsen et al. (1982) for extracting potassium from soil. A 2-g subsample of dried soil was removed from each sample, ground to a powder, and placed in a 50-ml polypropylene centrifuge tube with $20 \mathrm{ml}$ of $1 \mathrm{~N}$ ammonium acetate ( $\mathrm{pH}$ 7.0). The sample was vortexed at a high speed for $30 \mathrm{~s}$ and centrifuged at 4,000 rpm for $3 \mathrm{~min}$. Immediately after centrifugation, $10 \mathrm{ml}$ of supernatant was extracted from each sample and transferred to a new tube for analysis.

All dried plant samples were ground to a powder with an electric coffee bean grinder, and a 5-mg subsample was removed from each. Each subsample was placed in a 1.5-ml polypropylene centrifuge tube with $50 \mu \mathrm{l}$ of $70 \%$ nitric acid. After $12 \mathrm{~h}$ of digestion at room temperature, each tube was placed in a dry bath for $1 \mathrm{~h}$ at $80^{\circ} \mathrm{C}$, after which $10 \mu \mathrm{l}$ of the digest was transferred to a new tube containing $340 \mu$ l of double-distilled water for analysis.

The beetles were prepared by drying individuals for $24 \mathrm{~h}$ at $80^{\circ} \mathrm{C}$. After drying, individual beetles were weighed and placed in a $1.5-\mathrm{ml}$ polypropylene centrifuge tube with $75 \mu \mathrm{l}$ of $70 \%$ nitric acid. After $12 \mathrm{~h}$ of digestion at room temperature, the tubes were placed in a dry bath for $1 \mathrm{~h}$ at $80^{\circ} \mathrm{C}$, after which $10 \mu$ l of the digest was transferred to a new tube containing $340 \mu \mathrm{l}$ of double distilled water, which was used for analysis.

$\mathrm{Rb}$ concentrations in the soil, plant, and beetle samples were measured in a graphite furnace by atomic absorption (AA) spectroscopy using a Varian FS220 atomic absorption spectrometer (Varian, Palo Alto, CA). An auto-sampler automatically dispensed a volume of $15 \mu \mathrm{l}$ of each sample into the pyrolytic-coated, partitioned, graphite tube, where the sample was heated to $2,000^{\circ} \mathrm{C}$ through a series of nine temperature steps. $\mathrm{Rb}$ content was measured by the amount of energy absorbed at $780.0 \mathrm{~nm}$. The standard solution was prepared by dissolving $\mathrm{RbCl}$ salt in $1 \%$ nitric acid. The analytical range for the AA was $10 \mathrm{ng} / \mathrm{ml}$. Samples with $\mathrm{Rb}$ concentrations above this range were manually diluted and reanalyzed. Rb concentrations were reported in ppm dry weight for each sample.

Analysis. Rb concentrations in the soil, plants, and beetles were initially tested for normality by year, sampling date, and treatment using the Shapiro-Wilk W-statistic $(P \leq 0.05)$ calculated with the univariate procedure in PC-SAS (SAS Institute 1999). Results indicated that only data from the untreated plots were normally distributed and that $\mathrm{Rb}$ concentrations within treatments were highly right-skewed (i.e., some samples with extremely high Rb concentrations). Standard transformation techniques were unsuccessful, so all data were analyzed using nonparametric randomized complete block analysis of variance (ANOVA) and the RANK procedure in PC-SAS $(P \leq 0.05) \quad$ (SAS Institute 1999). Nonparametric ANOVA is an alternative when the assumption of normality is not met and uses the rank of $\mathrm{Rb}$ concentrations among treatments, rather than their raw values, to calculate statistics (Conover and Iman 1981). Median $\mathrm{Rb}$ concentrations among treatments were compared using LSDs (LSD test; $P \leq 0.05$ ), and $95 \%$ CL calculated for treatment medians.

Rb Dynamics in Beetles. Three additional laboratory experiments were conducted to examine the $\mathrm{Rb}$ elimination and uptake rates in adult western corn 
rootworms. Sixteen translucent plastic 5.8-liter boxes were each filled with $2,000 \mathrm{ml}$ of dry, silty clay loam soil. Twelve boxes were each treated with $250 \mathrm{ml}$ of a 10,000 ppm RbCl solution (99\% purity; Aldrich, Milwaukee, WI). The remaining four boxes were untreated controls to which $250 \mathrm{ml}$ of distilled water were added. Contents of each box were thoroughly mixed until the soil was uniformly moistened. After mixing, $400 \mathrm{ml}$ of pregerminated corn seeds were evenly distributed on the soil surface of each box. The boxes were covered with lids and held at $21^{\circ} \mathrm{C}$ and a photoperiod of 16:8 (L:D) h. Beginning 6 d later, neonate western corn rootworm larvae were infested over a 6 -d period until a total of 125 larvae had been added per box. Larvae were obtained from a nondiapausing colony maintained at the USDA Agricultural Research Service, Northern Grains Insects Research Laboratory, in Brookings, SD. After infestation, the soil was kept moist by misting the surface of each box with distilled water as needed. Seedling leaves were trimmed at 2- to 3-d intervals during the period of larval development. Once pupae were detected, all vegetation was cut at the soil surface and removed from the boxes. Throughout the emergence period, beetles were collected daily from each box, separated by sex, and maintained in $28-\mathrm{cm}^{3}$ clear Plexiglas cages on a diet of fresh sweet corn ears and lettuce. Cages were held at $21^{\circ} \mathrm{C}$ and a photoperiod of 16:8 (L:D) $\mathrm{h}$. After $0,0.5,1,2,3,4$, and $5 \mathrm{~d}$ of feeding on the sweet corn and lettuce, 25 males and 25 females per time interval were removed from the cages and stored at $-20^{\circ} \mathrm{C}$, and their $\mathrm{Rb}$ concentration determined using methods described in the previous section. Endogenous concentrations of $\mathrm{Rb}$ in the beetles were determined from 25 male and 25 female beetles collected from the untreated larval rearing boxes.

A second experiment was conducted to determine how feeding on Rb-enriched corn foliage as adults affected $\mathrm{Rb}$ concentrations in beetles previously labeled with $\mathrm{Rb}$ as larvae. Approximately $100 \mathrm{ml}$ of pregerminated corn seeds were placed in the bottom of 300 -ml plastic pots without drain holes. The seeds were covered with $200 \mathrm{ml}$ of dry, silty clay loam soil. The soil was moistened by adding $50 \mathrm{ml}$ of a $10,000 \mathrm{ppm} \mathrm{RbCl}$ solution to each pot. Pots were held for $7-10 \mathrm{~d}$ at $22^{\circ} \mathrm{C}$ and a photoperiod of 12:12 (L:D) h. Soil in the pots was kept moist by adding distilled water as needed. A total of 80 male and 80 female beetles were collected from the 12 larval rearing boxes treated with $\mathrm{Rb}$. Males and females were placed in separate $28-\mathrm{cm}^{3}$ cages that each contained a pot of the Rb-enriched corn seedlings. After $0,0.5,1,2$, and $3 \mathrm{~d}$ of feeding on the $\mathrm{Rb}$-enriched seedlings, 16 beetles per time interval were removed from each cage and stored at $-20^{\circ} \mathrm{C}$, and their $\mathrm{Rb}$ concentration was determined.

A third experiment was conducted to examine the uptake of $\mathrm{Rb}$ in previously unlabeled beetles through their feeding on $\mathrm{Rb}$-enriched corn foliage. A total of 60 male and 60 female beetles were collected from the four larval rearing boxes not treated with $\mathrm{Rb}$. Males and females were placed in separate $28-\mathrm{cm}^{3}$ cages that each contained a single pot of the Rb-enriched corn
Table 1. Median ( $95 \%$ CL) concentrations of Rb (ppm dry weight) in soil at three depths, 2 and 21 wk after treatment

\begin{tabular}{lccc}
\hline \hline \multirow{2}{*}{$\begin{array}{c}\text { Treatment } \\
\text { (g Rb/30.5 cm row })\end{array}$} & \multicolumn{3}{c}{2 wk after treatment } \\
\cline { 2 - 4 } & $0-20 \mathrm{~cm}$ & $20-60 \mathrm{~cm}$ & $60-122 \mathrm{~cm}$ \\
\hline 4 d pretreatment & $6(5-7) \mathrm{a}$ & $13(9-14) \mathrm{a}$ & $10(8-14)$ \\
Untreated & $8(7-38) \mathrm{ab}$ & $10(9-11) \mathrm{a}$ & - \\
0.08 & $94(10-215) \mathrm{c}$ & $47(10-108) \mathrm{a}$ & - \\
0.40 & $23(6-443) \mathrm{bc}$ & $13(8-74) \mathrm{a}$ & - \\
0.80 & $131(19-188) \mathrm{c}$ & $31(11-59) \mathrm{a}$ & - \\
\multicolumn{4}{c}{$21 \mathrm{wk}$ after treatment } \\
4 d pretreatment & $6(5-7) \mathrm{a}$ & $13(9-14) \mathrm{a}$ & $10(8-14) \mathrm{a}$ \\
Untreated & $4(3-5) \mathrm{a}$ & $10(4-12) \mathrm{a}$ & $7(6-8) \mathrm{a}$ \\
0.08 & $5(4-36) \mathrm{a}$ & $11(6-12) \mathrm{a}$ & $9(6-13) \mathrm{a}$ \\
0.40 & $9(4-53) \mathrm{ab}$ & $13(8-15) \mathrm{a}$ & $11(7-13) \mathrm{a}$ \\
0.80 & $66(8-200) \mathrm{b}$ & $10(6-11) \mathrm{a}$ & $9(7-12) \mathrm{a}$ \\
\hline
\end{tabular}

Powdered $\mathrm{RbCl}$ was applied to the soil at three rates on 13 June 2000 , Mead, NE $(n=4)$.

For each sampling date, medians within columns followed by the same letter are not significantly different (LSD test; $P>0.05$ ).

seedlings. After $0,0.5,1,2$, and $3 \mathrm{~d}$ of feeding, 8-12 beetles per time interval were removed from the cages and stored at $-20^{\circ} \mathrm{C}$, and their $\mathrm{Rb}$ concentration was determined. $\mathrm{Rb}$ elimination and uptake rates in beetles were described with nonlinear regression models developed with SigmaPlot (SPSS Inc. 1999).

\section{Results}

Field Study 2000. Rb application rate significantly affected $\mathrm{Rb}$ concentrations in the soil measured $2 \mathrm{wk}$ after treatment $(F=7.76 ; \mathrm{df}=4,27 ; P<0.01)$. However, neither depth nor the rate $\times$ depth interaction was significant $(P>0.05)$. While all three rates significantly elevated median $\mathrm{Rb}$ concentrations in the upper $20 \mathrm{~cm}$ of soil compared with the level $4 \mathrm{~d}$ before treatment, the largest increase (20-fold) was observed for the highest rate of $\mathrm{Rb}$ applied (Table 1). Below $20 \mathrm{~cm}$, there were no significant differences in the median $\mathrm{Rb}$ concentration of soil between treatments for samples extracted $2 \mathrm{wk}$ after treatment (Table 1).

Analysis of soil extracted $21 \mathrm{wk}$ after treatment indicated both a significant rate $(F=4.20 ; \mathrm{df}=4,42$; $P<0.01)$ and depth $(F=3.74 ; \mathrm{df}=2,42 ; P=0.03)$ effect on $\mathrm{Rb}$ concentrations of soil. However, the rate $\times$ depth interaction was not significant $(P>0.05)$. On this date, comparison of treatment medians showed that $\mathrm{Rb}$ concentrations in the upper $20 \mathrm{~cm}$ had declined to levels equivalent to that measured $4 \mathrm{~d}$ before treatment for all but the highest $\mathrm{Rb}$ rate (Table 1$)$. At this rate $(0.80 \mathrm{~g} \mathrm{Rb} / 30.5 \mathrm{~cm}$ row $)$, the median $\mathrm{Rb}$ concentration in the upper $20 \mathrm{~cm}$ of soil remained 10 -fold above the concentration measured $4 \mathrm{~d}$ before treatment (Table 1 ). At depths below $20 \mathrm{~cm}$, however, median $\mathrm{Rb}$ concentrations for all rates were equivalent to the level observed $4 \mathrm{~d}$ before treatment (Table 1).

The naturally occurring concentration of $\mathrm{Rb}$ in the plants $4 \mathrm{~d}$ before treatment was uniformly distributed across the three plant parts sampled, with median concentrations in the roots, stalks, and leaves equivalent to $6 \mathrm{ppm}$ (Table 2). Analysis of plant samples 
Table 2. Median (95\% CL) concentrations of Rb (ppm dry weight) in roots, stalks, and leaves of corn plants 2 and 8 wk after treatment

\begin{tabular}{cccc}
\hline \hline \multirow{2}{*}{$\begin{array}{c}\text { Treatment } \\
\text { g Rb/30.5 cm row })\end{array}$} & \multicolumn{2}{c}{ 2 woot after treatment (10 leaf-stage) } \\
\cline { 2 - 4 } & $6(5-8) \mathrm{a}$ & $6(5-8) \mathrm{a}$ & $6(5-7) \mathrm{a}$ \\
4 d pretreatment & $9(6-16) \mathrm{b}$ & $24(22-29) \mathrm{b}$ & $9(4-14) \mathrm{b}$ \\
Untreated & $22(9-42) \mathrm{c}$ & $23(13-55) \mathrm{b}$ & $12(8-56) \mathrm{b}$ \\
0.08 & $17(11-37) \mathrm{c}$ & $37(17-55) \mathrm{b}$ & $9(7-35) \mathrm{b}$ \\
0.40 & $17(11-39) \mathrm{c}$ & $41(16-80) \mathrm{b}$ & $9(7-43) \mathrm{b}$ \\
0.80 & 8 wk after treatment (post-pollination $)$ \\
& $6(5-8) \mathrm{a}$ & $6(5-8) \mathrm{a}$ & $6(5-7) \mathrm{a}$ \\
4 d pretreatment & $6(5-8) \mathrm{a}$ & $5(4-14) \mathrm{a}$ & $4(3-7) \mathrm{a}$ \\
Untreated & $29(7-107) \mathrm{b}$ & $8(5-18) \mathrm{a}$ & $7(5-13) \mathrm{a}$ \\
0.08 & $14(11-246) \mathrm{b}$ & $8(5-29) \mathrm{a}$ & $6(4-51) \mathrm{a}$ \\
0.40 & $121(66-1422) \mathrm{c}$ & $25(10-133) \mathrm{b}$ & $19(7-76) \mathrm{b}$ \\
0.80 & & & \\
\hline
\end{tabular}

Powdered $\mathrm{RbCl}$ was applied to the soil at three rates on 13 June 2000 , Mead, NE $(n=16)$.

For each sampling date, medians within columns followed by the same letter are not significantly different (LSD test; $P>0.05$ ).

taken 2 wk after treatment indicated both a significant rate $(F=27.69$; $\mathrm{df}=4,102 ; P<0.01)$ and plant part ( $F=19.82 ;$ df $=2,102 ; P<0.01)$ effect on Rb concentrations in the plants. However, the rate $\times$ plant part interaction was not significant on either sampling date $(P>0.05)$. Two weeks after treatment, all three $\mathrm{Rb}$ application rates significantly increased median $\mathrm{Rb}$ concentrations in the roots above the concentration in the untreated control (Table 2). There were no significant differences, however, between treatments for median $\mathrm{Rb}$ concentrations in the stalks or leaves on this date (Table 2).

Analysis of plant samples taken $8 \mathrm{wk}$ after treatment also revealed significant rate $(F=27.57$; $\mathrm{df}=4,102$; $P<0.01)$ and plant part $(F=14.73$; df $=2,102 ; P<$ 0.01 ) effects on $\mathrm{Rb}$ concentrations in the plants. On this date, all three application rates significantly elevated median $\mathrm{Rb}$ concentrations in the roots, with the highest rate increasing the median concentration 20fold over the concentration in the untreated roots (Table 2). In the stalks and leaves, however, only the highest rate maintained median $\mathrm{Rb}$ concentrations that were significantly greater than concentrations measured $4 \mathrm{~d}$ before treatment (Table 2). These results suggest that Rb applied to the soil as a powder may not be readily available for uptake by the plants, because the maximum concentration in the roots was not observed until 8 wk after treatment.

None of the $\mathrm{Rb}$ application rates significantly reduced western corn rootworm survival from egg to adult compared with survival on untreated plants ( $\mathrm{Ta}-$ ble 3). Across treatments, survival rates ranged from 2 to $4 \%$, which were very comparable to levels reported by Elliott et al. (1989) for western corn rootworm eggs infested in the field with a similar technique. The Rb concentration in newly emerged beetles from untreated plants averaged $2 \pm 3$ ppm dry weight. All three $\mathrm{Rb}$ application rates produced beetles with median $\mathrm{Rb}$ concentrations significantly greater than the median concentration in untreated beetles (Table 3). However, the percentage of newly emerged beetles that were labeled above the baseline concentration of 11 ppm (untreated mean +3 SD) was relatively low. Percentages that were positively labeled from the low, medium, and high $\mathrm{Rb}$ application rates were only 18 , 23 , and $27 \%$, respectively. The low labeling efficiency in beetles could relate to the delayed $\mathrm{Rb}$ uptake observed in the plants. Maximum Rb concentrations in the roots were not observed until $8 \mathrm{wk}$ after treatment, which was after most of the larvae had completed development. Additionally, there were no significant differences in the average dry weight of beetles between treatments (Table 3 ). This suggests that at least one beetle fitness parameter, beetle size, was not negatively impacted by exposure to Rb-treated corn as larvae.

Field Study 2001. In 2001, the naturally occurring median concentration of $\mathrm{Rb}$ in the soil ( $8 \mathrm{ppm})$ was comparable to the endogenous median concentration observed in 2000 (10 ppm). However, application of $\mathrm{Rb}$ in solution greatly enhanced concentrations in the soil compared with the dry formulation applied in 2000. Analysis of soil extracted $5 \mathrm{wk}$ after treatment indicated a significant treatment $\times$ depth interaction $(F=3.05$; df $=3,85 ; P=0.03)$. On this date, application of $\mathrm{Rb}$ in solution to the soil, whorl, or to both locations (soil + whorl) each resulted in median $\mathrm{Rb}$

Table 3. Mean ( \pm SE) dry weights, median (95\% CL) Rb concentrations, total number of beetles emerged, and survival rate from egg to adulthood for western corn rootworm adults reared on corn labeled with three rates of $\mathrm{RbCl}$ in 2000 and three application methods in 2001 , Mead, NE

\begin{tabular}{|c|c|c|c|c|c|c|}
\hline Year & Treatment $^{a}$ & $n$ & $\begin{array}{c}\text { Beetle dry } \\
\text { weight }(\mathrm{mg})\end{array}$ & $\begin{array}{l}\text { Median beetle [Rb] } \\
\text { (ppm dry weight) }\end{array}$ & $\begin{array}{c}\text { Total } \\
\text { emerged }\end{array}$ & Survival $(\%)^{b}$ \\
\hline \multirow[t]{4}{*}{2000} & Untreated & 66 & $2.2 \pm 0.13 \mathrm{a}$ & $2(1-2) a$ & 123 & $2.2 \pm 0.52 \mathrm{a}$ \\
\hline & $0.08 \mathrm{~g} \mathrm{Rb}$ & 65 & $2.1 \pm 0.12 \mathrm{a}$ & $5(3-7) b c$ & 139 & $2.5 \pm 0.84 a$ \\
\hline & $0.40 \mathrm{~g} \mathrm{Rb}$ & 82 & $2.1 \pm 0.10 \mathrm{a}$ & $4(3-6) b$ & 130 & $2.3 \pm 0.39 \mathrm{a}$ \\
\hline & $0.80 \mathrm{~g} \mathrm{Rb}$ & 102 & $2.2 \pm 0.09 a$ & $6(5-8) c$ & 203 & $3.6 \pm 0.89 a$ \\
\hline \multirow[t]{4}{*}{2001} & Untreated & 105 & $2.4 \pm 0.10 \mathrm{a}$ & $1(1-2) a$ & 274 & $5.7 \pm 0.99 \mathrm{a}$ \\
\hline & Soil & 56 & $2.5 \pm 0.13 \mathrm{a}$ & $12(8-18) b$ & 177 & $3.7 \pm 0.52 \mathrm{ab}$ \\
\hline & Whorl & 57 & $2.7 \pm 0.15 \mathrm{a}$ & $41(10-76) b c$ & 106 & $2.2 \pm 0.80 \mathrm{~b}$ \\
\hline & Soil + whorl & 85 & $2.7 \pm 0.13 a$ & $142(48-229) \mathrm{c}$ & 188 & $3.8 \pm 1.23 \mathrm{ab}$ \\
\hline
\end{tabular}

For each year, values within a column followed by the same letter are not significantly different (LSD test; $P>0.05)$.

${ }^{a}$ In $2000, \mathrm{RbCl}$ applied as powder to soil at base of each plant ( $\mathrm{g} \mathrm{Rb} / 30.5 \mathrm{~cm}$ row). In 2001, RbCl was applied in solution to either the soil ( $1 \mathrm{~g} \mathrm{Rb} /$ plant), directed into the whorl (1 g Rb/plant), or to both locations ( $2 \mathrm{~g} \mathrm{Rb} / \mathrm{plant}$ ).

${ }^{b}$ In 2000 and 2001, western corn rootworm eggs artificially infested at 350 and 200 eggs per plant, respectively. 
Table 4. Median ( $95 \%$ CL) concentrations of Rb (ppm dry weight) in soil at two depths 5 and 8 wk after treatment

\begin{tabular}{lcc}
\hline \hline \multirow{2}{*}{ Treatment } & \multicolumn{2}{c}{5 wk after treatment } \\
\cline { 2 - 3 } & $0-20 \mathrm{~cm}$ & $20-60 \mathrm{~cm}$ \\
\hline Untreated & $8(6-10) \mathrm{a}$ & $8(7-10) \mathrm{a}$ \\
Soil $(1 \mathrm{~g} \mathrm{Rb} / \mathrm{plant})$ & $35(13-199) \mathrm{b}$ & $24(18-37) \mathrm{b}$ \\
Whorl $(1 \mathrm{~g} \mathrm{Rb} / \mathrm{plant})$ & $34(15-98) \mathrm{b}$ & $10(9-19) \mathrm{c}$ \\
Soil + whorl $(2 \mathrm{~g} \mathrm{Rb} /$ plant $)$ & $296(20-639) \mathrm{b}$ & $54(18-127) \mathrm{b}$ \\
& \multicolumn{2}{c}{$8 \mathrm{wk}$ after treatment } \\
Untreated & $9(7-10) \mathrm{a}$ & $10(9-11) \mathrm{a}$ \\
Soil $(1 \mathrm{~g} \mathrm{Rb} / \mathrm{plant})$ & $68(23-304) \mathrm{bc}$ & $18(15-52) \mathrm{b}$ \\
Whorl $(1 \mathrm{~g} \mathrm{Rb} /$ plant $)$ & $61(28-273) \mathrm{b}$ & $22(13-40) \mathrm{b}$ \\
Soil + whorl $(2 \mathrm{~g} \mathrm{Rb} /$ plant $)$ & $317(80-771) \mathrm{c}$ & $22(17-56) \mathrm{b}$ \\
\hline
\end{tabular}

$\mathrm{RbCl}$ was applied in solution on 7 June 2001 either to the soil, directed into the whorl, or to both locations, Mead, NE $(n=12)$.

For each sampling date, medians within columns followed by the same letter are not significantly different (LSD test; $P>0.05$ ).

concentrations at both depths that were significantly elevated above concentrations in the untreated plots (Table 4). The significant treatment $\times$ depth interaction was attributed to median $\mathrm{Rb}$ concentrations for the untreated control and soil treatment remaining constant across depths, while median concentrations declined with depth for the whorl and soil + whorl treatments (Table 4). Although the rate of $\mathrm{Rb}$ applied was doubled for the soil + whorl treatment, the median $\mathrm{Rb}$ concentration in the upper $20 \mathrm{~cm}$ of soil was not significantly different from each application method alone (Table 4). Interestingly, these data also suggest that when $\mathrm{Rb}$ is applied only to the whorl, it can be translocated to the roots and exuded into the soil.

Analysis of soil extracted $8 \mathrm{wk}$ after treatment also showed a significant treatment $\times$ depth interaction $(F=5.69 ; \mathrm{df}=3,85 ; P<0.01)$. The interaction was explained by differential rates of decline in $\mathrm{Rb}$ content at increasing depth among treatments (Table 4). Additionally, all three $\mathrm{Rb}$ treatments did significantly elevate median $\mathrm{Rb}$ concentrations of soil at both depths above the concentration of the untreated control (Table 4), with the highest concentration present in the upper $20 \mathrm{~cm}$ for the soil + whorl treatment. These data indicate that elevated $\mathrm{Rb}$ concentrations in the upper $20 \mathrm{~cm}$ of soil can be maintained throughout the period of peak larval development by applying $\mathrm{Rb}$ in solution to both the soil and whorl of corn plants.

Application of $\mathrm{Rb}$ in solution also appeared to enhance $\mathrm{Rb}$ uptake by the corn plants. Analysis of plants $5 \mathrm{wk}$ after treatment indicated that all three treatments significantly increased median Rb concentrations in all plant parts above concentrations in the untreated control (Table 5). For all treatments, median $\mathrm{Rb}$ concentrations were also numerically higher in the roots compared with the above-ground plant parts (Table 5). Roots from the soil + whorl treatment contained a median $\mathrm{Rb}$ concentration that was 150 fold greater than the concentration in untreated roots (Table 5). There was also a significant treatment $\times$ plant part interaction on $\mathrm{Rb}$ concentration $(F=2.74$; $\mathrm{df}=12,217 ; P<0.01)$. For the untreated control and soil treatment, median $\mathrm{Rb}$ concentrations declined from the roots to the lower stalk and remained at relatively low and consistent levels across all the above-ground plant parts (Table 5). For the whorl and soil + whorl treatments, however, median $\mathrm{Rb}$ concentrations declined from the roots to the lower stalk, but remained relatively high across the remaining three above-ground plant parts (Table 5). These data seem to indicate greater translocation of $\mathrm{Rb}$ downward from the foliage to the roots compared with upward movement from the roots to the foliage.

Although $\mathrm{Rb}$ content had declined by 8 wk after treatment, all three treatments maintained $\mathrm{Rb}$ concentrations in all plant parts that were significantly elevated above concentrations in untreated plants (Table 5). Except for the lower leaf, application of $\mathrm{Rb}$ to both the soil and whorl of plants provided superior $\mathrm{Rb}$ concentrations in all plant parts compared with the application of $\mathrm{Rb}$ to each location alone (Table 5). These data also suggest that elevated $\mathrm{Rb}$ concentrations in the roots can be maintained throughout the period of peak larval development by applying $\mathrm{Rb}$ in solution to both the soil and whorl of corn plants.

Application of Rb in solution dramatically improved detectable $\mathrm{Rb}$ concentrations in adult western corn rootworms compared with the dry formulation of $\mathrm{RbCl}$ applied in 2000 (Table 3). The highest median

Table 5. Median (95\% CL) concentrations of Rb (ppm dry weight) in the root, lower stalk, lower leaf, upper stalk, and upper leaf of corn plants 5 and 8 wk after treatment

\begin{tabular}{|c|c|c|c|c|c|}
\hline \multirow{2}{*}{ Treatment } & \multicolumn{5}{|c|}{5 wk after treatment (13 July) } \\
\hline & Root & Lower stalk & Lower leaf & Upper stalk & Upper leaf \\
\hline Untreated & $38(20-55) \mathrm{a}$ & $12(10-16) \mathrm{a}$ & $12(8-18) \mathrm{a}$ & $21(17-38) \mathrm{a}$ & $11(7-18) \mathrm{a}$ \\
\hline Soil & $1426(486-2037) b$ & $178(135-258) b$ & $150(59-230) \mathrm{b}$ & $340(219-556) \mathrm{b}$ & $213(109-409) b$ \\
\hline Whorl & $2295(1694-6844) \mathrm{c}$ & $736(537-1882) \mathrm{c}$ & $2017(1643-3598) \mathrm{c}$ & $868(557-3932) \mathrm{c}$ & $730(457-2247) \mathrm{c}$ \\
\hline \multirow[t]{2}{*}{ Soil + whorl } & $5860(3561-7078) \mathrm{c}$ & $932(677-2234) \mathrm{c}$ & $2052(1069-3375) \mathrm{c}$ & $2334(1493-4229) d$ & $1514(1220-2831) \mathrm{d}$ \\
\hline & \multicolumn{5}{|c|}{8 wk after treatment (1 August) } \\
\hline Untreated & $11(5-18) \mathrm{a}$ & $4(3-6) \mathrm{a}$ & $6(5-8) a$ & $6(4-10) \mathrm{a}$ & $7(4-8) a$ \\
\hline Soil & $1303(633-2052) b$ & $75(41-106) b$ & $71(43-98) b$ & $123(52-161) \mathrm{b}$ & $109(62-188) b$ \\
\hline Whorl & $1840(835-3636) b$ & $369(121-536) \mathrm{c}$ & $1806(473-3993) \mathrm{c}$ & $368(99-757) \mathrm{c}$ & $545(196-668) \mathrm{c}$ \\
\hline Soil + whorl & $2774(2582-6411) \mathrm{c}$ & $649(215-734) \mathrm{d}$ & $1268(483-2435) \mathrm{c}$ & $552(231-1182) \mathrm{d}$ & $788(405-2001) d$ \\
\hline
\end{tabular}

$\mathrm{RbCl}$ was applied in solution on 7 June 2001 either to the soil ( $1 \mathrm{~g} \mathrm{Rb} /$ plant), directed into the whorl ( $1 \mathrm{~g}$ Rb/plant), or to both locations ( 2 g Rb/plant), Mead, NE $(n=12)$.

For each sampling date, medians within columns followed by the same letter are not significantly different (LSD test; $P>0.05)$. 


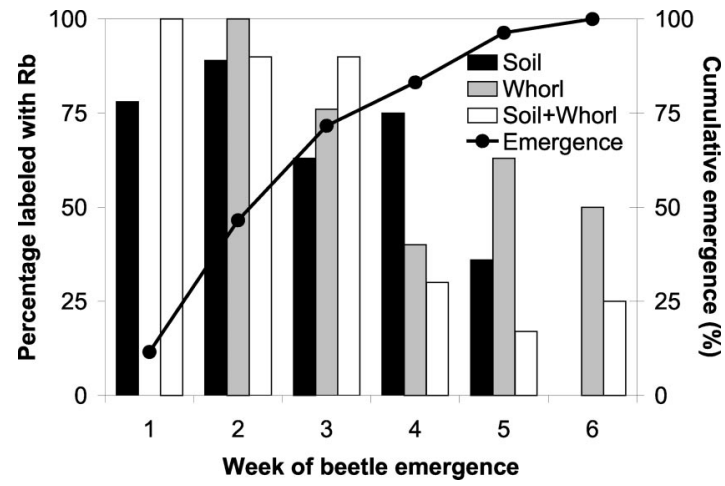

Fig. 1. Weekly (11 July-17 August) percentage of newly emerged western corn rootworm adults with $\mathrm{Rb}$ concentrations above the baseline concentration of untreated beetles (5 ppm dry weight). $\mathrm{RbCl}$ was applied in solution to either the soil ( $1 \mathrm{~g} \mathrm{Rb} /$ plant), directed into the whorl $(1 \mathrm{~g} \mathrm{Rb} /$ plant), or to both locations (2 g Rb/plant). Mead, NE, 2001.

$\mathrm{Rb}$ concentration in beetles was obtained with the soil + whorl treatment. However, this Rb concentration was not statistically different from the concentration achieved with the whorl treatment alone ( $\mathrm{Ta}$ ble 3). There were no significant differences in the dry weights of beetles between treatments, and survival from egg to adult was generally unaffected by the treatments (Table 3). However, the whorl treatment alone did significantly reduce adult emergence relative to the untreated control (Table 3).

In 2001, initial beetle emergence occurred on 11 July, nearly 5 wk after the $\mathrm{Rb}$ treatments were applied, and continued for $6 \mathrm{wk}$. The mean \pm SD Rb concentration of the untreated beetles was $2 \pm 1 \mathrm{ppm}$ dry weight. The baseline $\mathrm{Rb}$ concentration above which a beetle was considered labeled was 5 ppm, equivalent to $3 \mathrm{SD}$ above the mean of the untreated beetles. All three treatments produced beetles that were positively labeled throughout the 6 -wk emergence period (Fig. 1). However, when Rb was applied both to the soil and the whorl, $90 \%$ or more of the beetles that emerged during the first $3 \mathrm{wk}$ contained $\mathrm{Rb}$ concentrations above the baseline concentration (Fig. 1). This represents a significant proportion of the population that was labeled, considering emergence was $72 \%$ complete by this time (Fig. 1).

$\mathrm{Rb}$ Dynamics in Beetles. $\mathrm{Rb}$ concentrations in newly emerged beetles reared on roots of Rb-treated corn seedlings as larvae and transferred to a clean diet declined exponentially (Fig. 2). Rb concentrations were not significantly different between males and females $(F=0.59 ; \mathrm{df}=1,132 ; P>0.05)$, so a single elimination curve was fitted to data across sexes (Fig. 2). The mean $\pm \mathrm{SD} \mathrm{Rb}$ concentration of untreated beetles was $1.4 \pm 1 \mathrm{ppm}$ dry weight. Based on these values, the baseline $\mathrm{Rb}$ concentration above which a beetle was considered labeled was $4 \mathrm{ppm}$ $($ mean $+3 \mathrm{SD})$. This was very comparable to the baseline concentration of $5 \mathrm{ppm}$ obtained in the 2001 field study. If a baseline concentration of $5 \mathrm{ppm}$ were assumed, labeled beetles would remain distinguish-

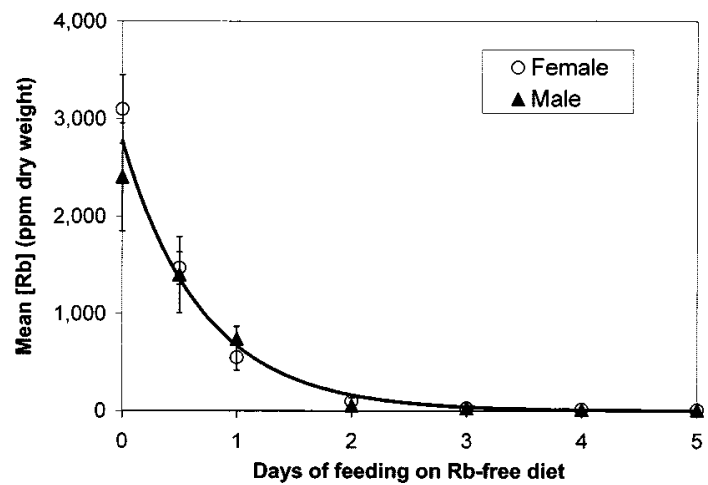

Fig. 2. Rb elimination rate in western corn rootworm adults after being reared on Rb-enriched corn seedlings as larvae and transferred to a clean diet of sweet corn and lettuce at emergence. Elimination followed an exponential decay model: $y=2,722 e^{(-1.42 * x)} ;\left(R^{2}=0.99 ; n=20\right)$.

able from unlabeled beetles in the population for up to $4.5 \mathrm{~d}$ postemergence. However, the mean $\mathrm{Rb}$ concentration of newly emerged beetles under laboratory conditions $(2,772 \mathrm{ppm})$ was considerably greater than the highest mean $\mathrm{Rb}$ concentration obtained in the field ( $427 \mathrm{ppm}$ for the soil + whorl treatment). If this difference in initial $\mathrm{Rb}$ concentrations were accounted for, based on the elimination curve, labeled beetles would remain distinguishable from unlabeled beetles for up to $3.2 \mathrm{~d}$ postemergence in the field.

A second laboratory study was conducted to determine if the $\mathrm{Rb}$ concentration in newly emerged beetles, previously labeled as larvae, could be elevated if the adults fed on Rb-enriched corn seedlings. $\mathrm{Rb}$ uptake rates for labeled males and females were not significantly different $(F=0.19 ; \mathrm{df}=1,33 ; P>0.05)$, so a single uptake curve was fitted to data from both sexes (Fig. 3A). After $1 \mathrm{~d}$ of feeding on Rb-enriched corn seedlings, the average $\mathrm{Rb}$ concentration in previously labeled beetles increased by $70 \%$ (Fig. 3A). There was a 5.5-fold increase in the $\mathrm{Rb}$ concentration of labeled beetles after feeding for $3 \mathrm{~d}$ (Fig. 3A). Although this experiment was conducted in the laboratory with seedling corn, these data suggest that the initial $\mathrm{Rb}$ concentration in beetles on emergence would be enhanced by feeding on labeled corn plants in the vicinity of their emergence site. Elevated initial $\mathrm{Rb}$ concentrations could then potentially extend the time-period beetles remain labeled in the field.

$\mathrm{Rb}$ concentrations in newly emerged, unlabeled beetles increased asymptotically with time after feeding on Rb-enriched corn seedlings (Fig. 3B). Rb uptake was significantly greater for females compared with males $(F=9.51 ; \mathrm{df}=1,41 ; P<0.01)$, and separate uptake curves were developed for each sex. Assuming a baseline $\mathrm{Rb}$ concentration of 5 ppm (2001 field study), unlabeled male and female beetles would acquire sufficient $\mathrm{Rb}$ to be labeled after $<1 \mathrm{~min}$ of feeding on $\mathrm{Rb}$-enriched corn seedlings. If the mean $\mathrm{Rb}$ concentration of newly emerged, labeled beetles reared in the laboratory is used as a benchmark 

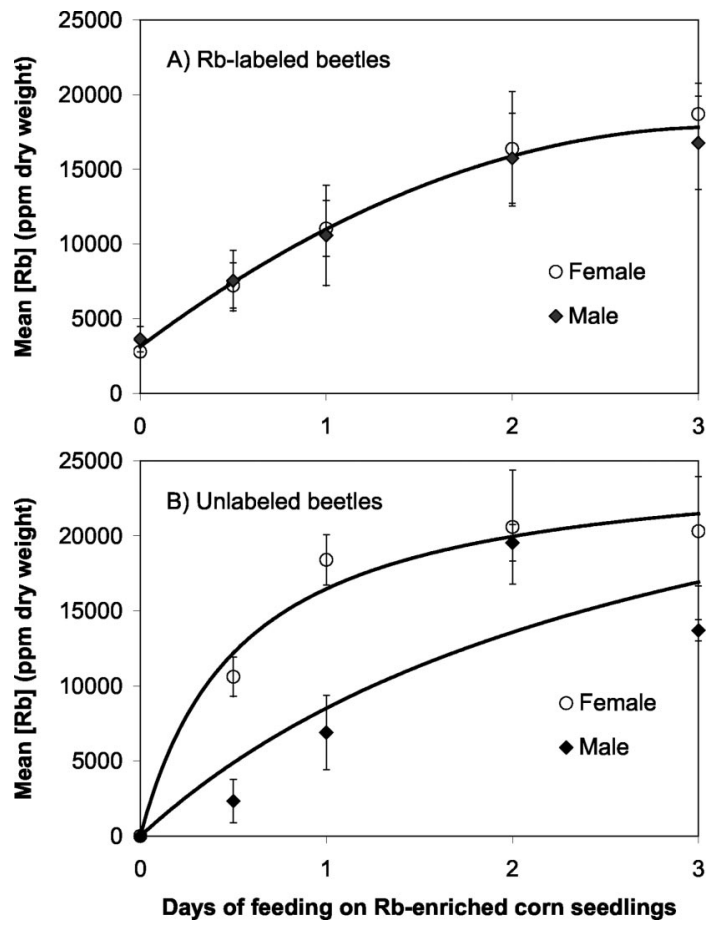

Fig. 3. Rb uptake in newly emerged western corn rootworm adults reared as larva on either (A) Rb-treated corn seedlings or (B) untreated corn seedlings, and caged on $\mathrm{Rb}$-enriched corn seedlings for up to $3 \mathrm{~d}$ postemergence. $\mathrm{Rb}$ uptake in labeled beetles (A) followed a quadratic polynomial: $y=3,121+(9,360 * x)+\left(-1,488 * x^{2}\right) ;\left(R^{2}=0.99 ; n=\right.$ 8). Uptake in unlabeled beetles (B) followed a rectangular hyperbola for males: $y=33,399 * x /(2.92+x) ;\left(R^{2}=0.79\right.$; $n=4)$; and females: $y=25,336 * x /(0.54+x) ;\left(R^{2}=0.97\right.$; $n=4)$.

(2,882 ppm), unlabeled male and female beetles would acquire equivalent levels of $\mathrm{Rb}$ in 6.5 and $1.7 \mathrm{~h}$ of feeding on Rb-enriched corn seedlings, respectively.

\section{Discussion}

Our results are in agreement with previous studies that show Rb is highly mobile and readily translocated throughout the corn plant. However, most previous studies in corn have focused on foliar applications of $\mathrm{Rb}$ to label lepidopteran pests that feed as larvae on above-ground plant parts (Graham et al. 1978b, Legg and Chiang 1984, Stimmann 1991). These studies demonstrate the feasibility of enriching corn plants with $\mathrm{Rb}$ in the field, either through $\mathrm{Rb}$ application to the soil, whorl, or both, with subsequent transfer of the $\mathrm{Rb}$ to western corn rootworm adults that complete development as larvae feeding on the roots. Application of $\mathrm{Rb}$ in solution both to the soil around the base of the plant and directed into the whorl provided the highest concentration of $\mathrm{Rb}$ in newly emerged beetles compared with the other application methods tested. At least $90 \%$ of the beetles that emerged from this treat- ment during the first $3 \mathrm{wk}$ of the emergence period contained $\mathrm{Rb}$ levels above the baseline concentration calculated from the untreated beetles.

In both years, there were no significant differences in the dry weights of beetles that completed development on Rb-enriched corn compared with beetles from untreated corn. Previous studies with several lepidopteran species report no adverse fitness effects until $\mathrm{Rb}$ concentrations in their diet increased above 10,000 ppm (Van Steenwyk 1991). In this study, median $\mathrm{Rb}$ concentrations in the roots approached only one-half that level when $\mathrm{Rb}$ was applied both to the soil and the whorl of the plants. This suggests that some beetle fitness parameters (i.e., size) were not negatively impacted by exposure to $\mathrm{Rb}$ as larvae.

The permanence of the mark is another factor that must be considered when determining the feasibility of a marking technique for dispersal studies (Berry et al. 1972, Van Steenwyk 1991). Western corn rootworm beetles labeled with $\mathrm{Rb}$ in the field should remain distinguishable from unlabeled beetles for up to $3.2 \mathrm{~d}$ postemergence. This time period is considerably shorter than the 10-14 d reported by Fleischer and Kirk (1994) for a related species, the southern corn rootworm, Diabrotica undecimpuntata howardi (Barber). However, in their study, beetles were caged and provided a diet of $\mathrm{Rb}$-treated cucurbit seedlings for $7 \mathrm{~d}$ (i.e., no-choice situation) before being transferred to clean cucurbit transplants. This resulted in initial $\mathrm{Rb}$ concentrations that were considerably higher $(12,789 \pm 458 \mathrm{ppm})$ than concentrations determined for newly emerged western corn rootworms $(2,772 \pm 51 \mathrm{ppm})$ and could explain the difference in $\mathrm{Rb}$ elimination rates between the two species. The primary advantage of the labeling method developed in the current study is that it ensures beetles are labeled at the time of their emergence from the soil. The technique does not require that newly emerged beetles feed to become labeled. This is especially important, given our ultimate objective of measuring the initial premating movement capabilities of beetles from their emergence site.

Previous studies have shown that primarily mated, preovipositional western corn rootworm females engage in dispersal (Godfrey and Turpin 1983, Coats et al. 1986, Naranjo 1990a, 1991). Quiring and Timmins (1990) concluded that most females mated within the first $24 \mathrm{~h}$ after emergence and observed that some females only moved within a few meters of their emergence site for mating. These observations, along with results from our laboratory experiments, do suggest that initial $\mathrm{Rb}$ concentrations could be significantly elevated if newly emerged beetles fed on $\mathrm{Rb}$-enriched corn plants in the vicinity of their emergence site. After $1 \mathrm{~d}$ of feeding on Rb-enriched corn seedlings, the average $\mathrm{Rb}$ concentration in labeled beetles increased by $70 \%$. Elevated initial Rb concentrations could then possibly extend the time-period beetles remain labeled in the field.

Only a single application of $\mathrm{Rb}$ was applied to the corn plants in both years of this study. Graham et al. (1978b) determined that by dividing the total Rb ap- 
plied into three weekly applications, Rb concentrations in both the corn plants and corn earworm larvae, Helicoverpa zea (Boddie), were initially higher, and remained elevated significantly longer, compared with the same amount of $\mathrm{Rb}$ in a single treatment. This suggests that by dividing the total amount of $\mathrm{Rb}$ applied over two to three applications, it may be possible to not only increase $\mathrm{Rb}$ concentrations in newly emerged beetles, but also increase the proportion of late-emerging beetles that are labeled.

The relatively short retention time of $\mathrm{Rb}$ in western corn rootworm beetles does not preclude this marking technique as useful for studying adult dispersal. It does, however, define the constraints associated with this marking technique. Even though the retentiontime of $\mathrm{Rb}$ is relatively short, the ability to efficiently label a large number of beetles with virtually no disruption of the population should allow this marking technique (application of $\mathrm{Rb}$ to both the soil and whorl of plants) to be useful for quantifying the shortrange, intrafield movement of western corn rootworm beetles from their emergence site. Additionally, because beetle emergence can last at least $6 \mathrm{wk}$ and $\mathrm{Rb}$ concentrations remain elevated in the corn plants for at least $8 \mathrm{wk}$, the short retention time of $\mathrm{Rb}$ in beetles will allow for repeated measurements of beetle movement throughout the season. Such information would reduce the uncertainty associated with the development of effective resistance management strategies for corn rootworms and transgenic corn. Quantifying parameters associated with corn rootworm movement within the cornfield also should be valuable in the development and validation of models used to help assess risk associated with the evolution of resistance in rootworm populations to new control technologies.

\section{Acknowledgments}

The authors thank J. Brown, N. Urban, and T. Laudenback for assistance in the field, and T. Spencer and S. Siquiera for help with processing samples for Rb analysis. T. Heng-Moss and R. Wright provided valuable input on an earlier draft of this manuscript. This work was supported by a grant from the Agricultural Research Division of the University of Nebraska. This is University of Nebraska Agricultural Research Division journal series paper No. 14051 and contribution No. 1150 of the Department of Entomology, University of Nebraska.

\section{References Cited}

Akey, D. H. 1991. A review of marking techniques in arthropods and an introduction to elemental marking. Southwest. Entomol. Suppl. 14: 1-6.

Berry, W. L., M. W. Stimmann, and W. W. Wolf. 1972. Marking of native phytophagous insects with rubidium: a proposed technique. Ann. Entomol. Soc. Am. 65: 236-238.

Coats, S. A., J. J. Tollefson, and J. A. Mutchmor. 1986. Study of migratory flight in the western corn rootworm (Coleoptera: Chrysomelidae). Environ. Entomol. 15: 1-6.

Conover, W. J., and R. L. Iman. 1981. Rank transformations as a bridge between parametric and nonparametric statistics. Am. Statistician. 35: 124-129.

Darnell, S. J., L. J. Meinke, and L. J. Young. 2000. Influence of corn phenology on adult western corn rootworm
(Coleoptera: Chrysomelidae) distribution. Environ. Entomol. 29: 587-595.

Elliott, N. C., G. R. Sutter, T. F. Branson, and J. R. Fisher. 1989. Effect of population density of immatures on survival and development of the western corn rootworm (Coleoptera: Chrysomelidae). J. Entomol. Sci. 24: 209 213.

Fleischer, S. J., and D. Kirk. 1994. Kairomonal baits: effect on acquisition of a feeding indicator by Diabroticite vectors in cucurbits. Environ. Entomol. 23: 1138-1149.

Godfrey, L. D., and F. T. Turpin. 1983. Comparison of western corn rootworm (Coleoptera: Chrysomelidae) adult populations and economic thresholds in first-year and continuous cornfields. J. Econ. Entomol. 76: 1028-1032.

Graham, H. M., D. A. Wolfenbarger, and J. B. Nosky. 1978a. Labeling plants and their insect fauna with rubidium. Environ. Entomol. 7: 379-383.

Graham, H. M., D. A. Wolfenbarger, J. R. Nosky, N. S. Hernandez, Jr., J. R. Llanes, and J. A. Tamayo. 1978b. Use of rubidium to label corn earworm and fall armyworm for dispersal studies. Environ. Entomol. 7: 435-438.

Hayes, J. L. 1991. Elemental marking of arthropod pests in agricultural systems: single and multigenerational marking. Southwest. Entomol. Suppl. 14: 37-47.

Hill, R. E., and Z. B. Mayo. 1974. Trap corn to control corn rootworms. J. Econ. Entomol. 67: 748-750.

Hopper, K. R. 1991. Ecological applications of elemental labeling: Analysis of dispersal, density, mortality and feeding. Southwest. Entomol. Suppl. 14: 71-83.

International Life Sciences Institute. 1999. An evaluation of insect resistance management in Bt field corn: a sciencebased framework for risk assessment and risk management. ILSI Press, Washington, DC.

Jones, R. L. 1989. Rubidium in surface horizons of Illinois soils. Soil Sci. Soc. Am. J. 53: 588-591.

Knudsen, D., G. A. Peterson, and P. F. Pratt. 1982. Lithium, sodium, and potassium. pp. 228-230. In A. L. Page (ed.), Methods of soil analysis. Part 2: chemical and microbiological properties. American Society of Agronomy and Soil Science Society of America, Madison, WI.

Lance, D. R., and N. C. Elliott. 1990. Marking western corn rootworm beetles (Coleoptera: Chrysomelidae): effects on survival and a blind evaluation for estimating bias in mark-recapture data. J. Kansas Entomol. Soc. 63: 1-8.

Legg, D. E., and H. C. Chiang. 1984. Rubidium marking technique for the European corn borer (Lepidoptera: Pyralidae) in corn. Environ. Entomol. 13: 579-583.

Naranjo, S. E. 1990a. Comparative flight behavior of Diabrotica virgifera virgifera and Diabrotica barberi in the laboratory. Entomol. Exp. Appl. 55: 79-90.

Naranjo, S. E. 1990b. Influence of two mass-marking techniques on survival and flight behavior of Diabrotica virgifera virgifera (Coleoptera: Chrysomelidae). J. Econ. Entomol. 83: 1360-1364.

Naranjo, S. E. 1991. Movement of corn rootworm beetles, Diabrotica spp. (Coleoptera: Chrysomelidae), at cornfield boundaries in relation to sex, reproductive status, and crop phenology. Environ. Entomol. 20: 230-240.

Oloumi-Sadeghi, H., and E. Levine. 1990. A simple, effective, and low-cost method for mass marking adult western corn rootworms (Coleoptera: Chrysomelidae). J. Entomol. Sci. 25: 170-175.

Quiring, D. T., and P. R. Timmins. 1990. Influence of reproductive ecology on feasibility of mass trapping Diabrotica virgifera virgifera (Coleoptera: Chrysomelidae). J. Applied Ecol. 27: 965-982.

SAS Institute. 1999. SAS/STAT user's guide, version 8.0. SAS Institute, Cary, NC. 
Southwood, T.R.E. 1978. Ecological methods with particular reference to the study of insect populations. Chapman $\&$ Hall, London, England.

SPSS Inc. 1999. SigmaPlot for Windows, version 5.0. SPSS, Inc., Richmond, CA.

Stimmann, M. W. 1991. A personal history of the development of the rubidium marking technique. Southwest. Entomol. Suppl. 14: 9-13.

U.S. Environmental Protection Agency. 2002. FIFRA Scientific Advisory Panel, Meeting Minutes No. 2002-05B. Part B: Corn rootworm plant-incorporated protectant nontarget insect and insect resistance management issues: Insect resistance management issues. August 28-29, 2002.
Van Steenwyk, R. A. 1991. The uses of elemental marking for insect dispersal and mating competitiveness studies: from the laboratory to the field. Southwest. Entomol. Suppl. 14: 15-23.

Witkowski, J. F., J. C. Owens, and J. J. Tollefson. 1975. Diel activity and vertical flight distribution of adult western corn rootworms in Iowa cornfields. J. Econ. Entomol. 68: $351-352$.

Received for publication 31 March 2003; accepted 18 September 2003. 